\title{
Dual Anterior Descending Coronary Artery Associated with Coronary Artery Disease
}

\author{
Luciane da L. V. Siqueira, Ronaldo R. L. Bueno, Ênio E. Guérios, Paulo M. P. de Andrade, \\ Deborah C. Nercolini, Stefan W. Negrão, Álvaro L. A. Pacheco, José C. E. Tarastchuck \\ Curitiba, PR - Brazil
}

The patient is a male with risk factors for coronary artery disease, who was referred for cardiac catheterization after acute myocardial infarction in the inferior wall. The patient underwent transluminal coronary angioplasty in the right coronary artery with successful stent implantation.

Anomalies of the anterior descending coronary artery are angiographic findings usually associated with congenital heart diseases, such as tetralogy of Fallot and transposition of great vessels ${ }^{1}$.

The origin of the anterior descending coronary artery in the right sinus of Valsalva or in the right coronary artery is a rare anomaly with an incidence ranging from $0.03 \%$ to $0.2 \%$ of the patients undergoing routine catheterization ${ }^{2}$.

A dual anterior descending coronary artery is an exceptionally rare entity, and only 6 cases have been reported in the literature ${ }^{3-7}$.

We report the case of a dual anterior descending coronary artery associated with the presence of coronary artery disease.

\section{Case Report}

The patient is a 50-year-old white male referred to undergo cardiac catheterization, because of an acute myocardial infarction in the inferior wall occurring 12 days earlier. The patient had been treated in a conservative way in his city of origin.

The following risk factors for coronary artery disease wer found: systemic arterial hypertension, dyslipidemia, non insulin-dependent diabetes mellitus, and positive morbid familial history of coronary artery disease.

Hospital Universitário Evangélico de Curitiba

Mailing address: Luciane da Luz Veríssimo Siqueira - Av. Hercílio Luz, 1425/ 1203 - 88020-001 - Florianópolis, SC, Brazil - E-mail: 1lverissimo@cardiol.br English version by Stela Maris C. e Gandour
On hospital admission, the patient was asymptomatic. On physical examination, he was in good general condition, his blood pressure was normal, as were his cardiac and pulmonary auscultations. At the time of admission, his chest radiogram was normal, and the electrocardiogram showed an electrically inactive zone in the inferior wall.

Cardiac catheterization was performed according to the Judkins technique and showed the following: a dominant right coronary artery with an eccentric $90 \%$ lesion and a thrombus in its initial third, and an anterior descending coronary artery partially originating from the right coronary artery and partially from the trunk of the left coronary artery (fig. 1).

The anterior descending branch originating from the left coronary artery split after a short trajectory into a septal and a diagonal branch (fig. 2).

The portion of the anterior descending branch originating from the right coronary artery had an anomalous trajectory, passing in front of the pulmonary artery towards the anterior interventricular sulcus. From then on, the anatomic trajectory of the anterior descending branch continued, which was interrupted after the first diagonal branch from the left coronary trunk (fig. 3). Neither the anterior descending branch originating from the left coronary trunk nor the one originating from the right coronary artery had atherosclerotic lesions. No lesions were observed in the left coronary trunk or in the circumflex branch.

The left ventricular contraction was normal.

Right coronary angioplasty was proposed to the patient and was uneventfully performed, with successful primary stent implantation (figs. 4 and 5).

The patient had a good in-hospital evolution and was discharged from the hospital on the second day of hospitalization.

\section{Discussion}

Coronary arteries of anomalous origin are found in $1 \%$ to $2 \%$ of the population undergoing cardiac catheterization ${ }^{3}$. 


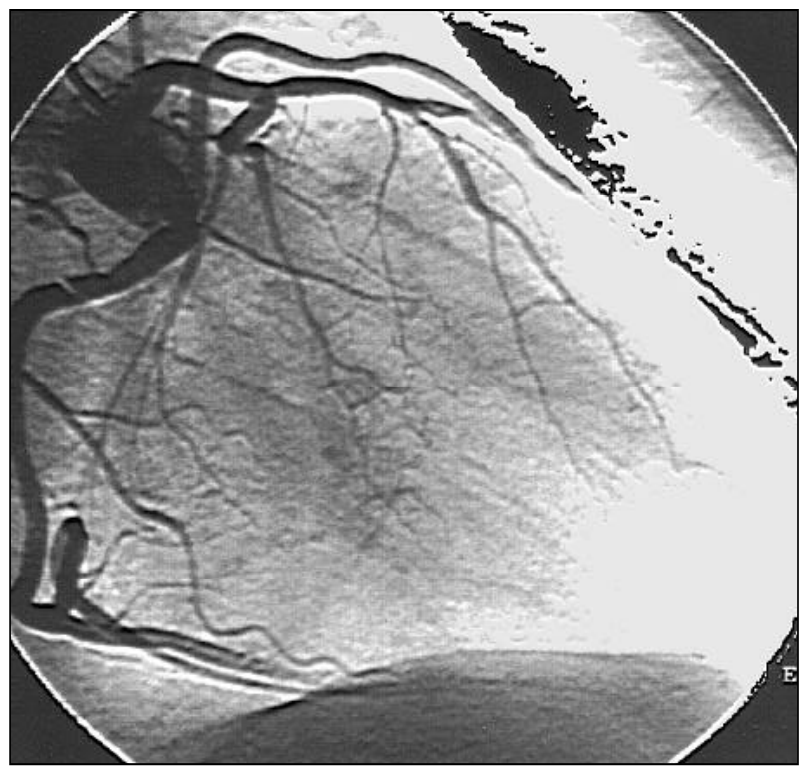

Fig. 1 - Right coronary artery with an eccentric $90 \%$ lesion in its initial third.

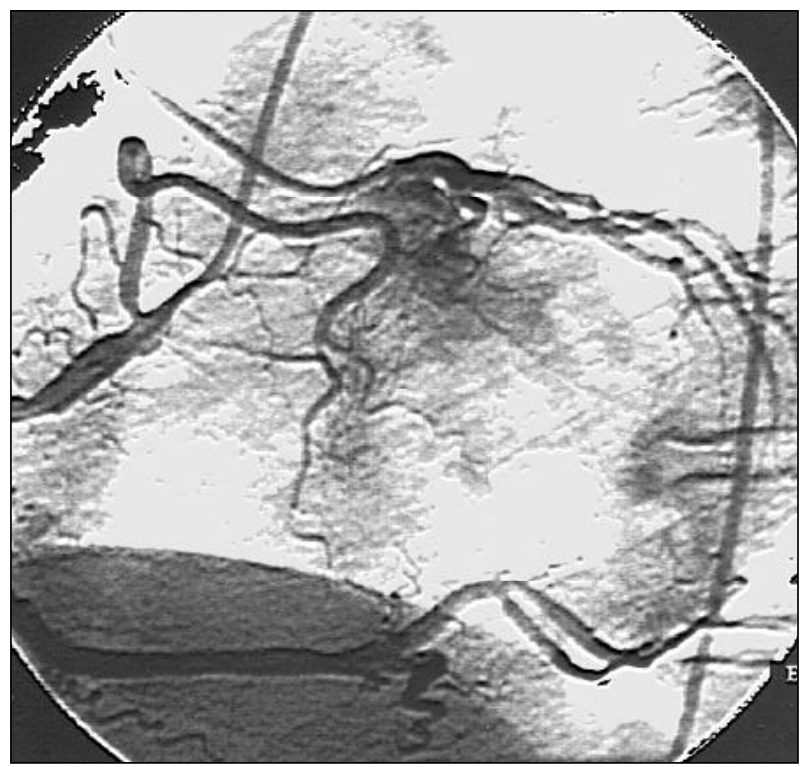

Fig. 2 - Left anterior descending coronary artery partially originating from the right coronary artery with an anomalous trajectory and passing in front of the pulmonary artery towards the anterior interventricular sulcus.

The most common is the origin of the circumflex artery from the right sinus of Valsalva or from the right coronary artery ${ }^{4}$. Traditionally, these anomalies are classified into the 6 subgroups shown in table $\mathrm{I}^{2}$.

Classically, no clinical consequences were attributed to those findings because the blood flow in the anomalous coronary artery is usually normal.

Anomalies associated with changes in blood flow may result in sudden death, myocardial ischemia, and acute myocardial infarction. Some of those anomalies are as follows: coronary artery fistulas, origin of the left coronary artery from the pulmonary artery or from the right

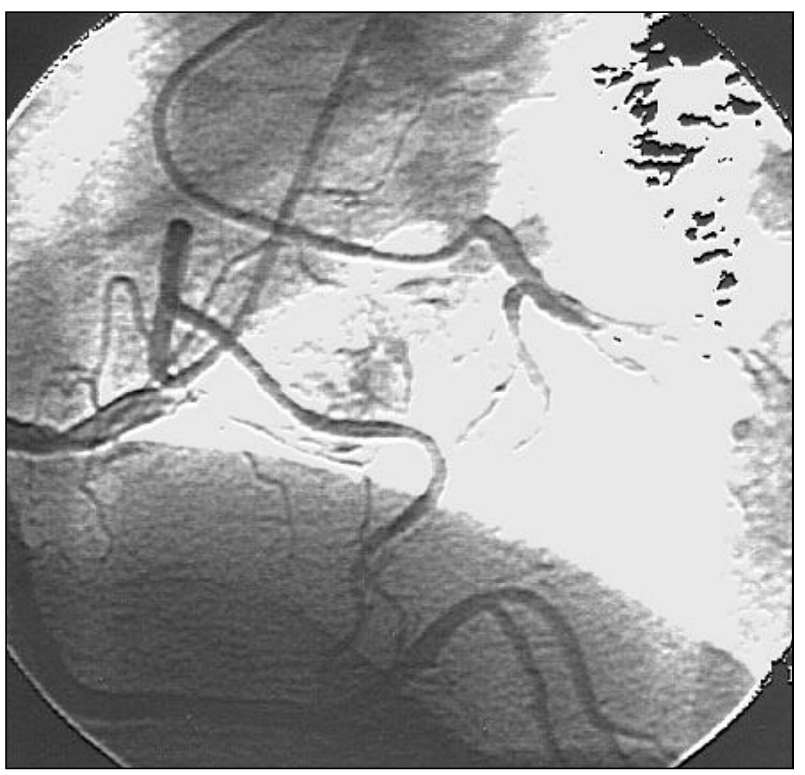

Fig. 3 - Anterior descending coronary artery originating from the left coronary artery and dividing after a short trajectory into a septal and a diagonal branch.

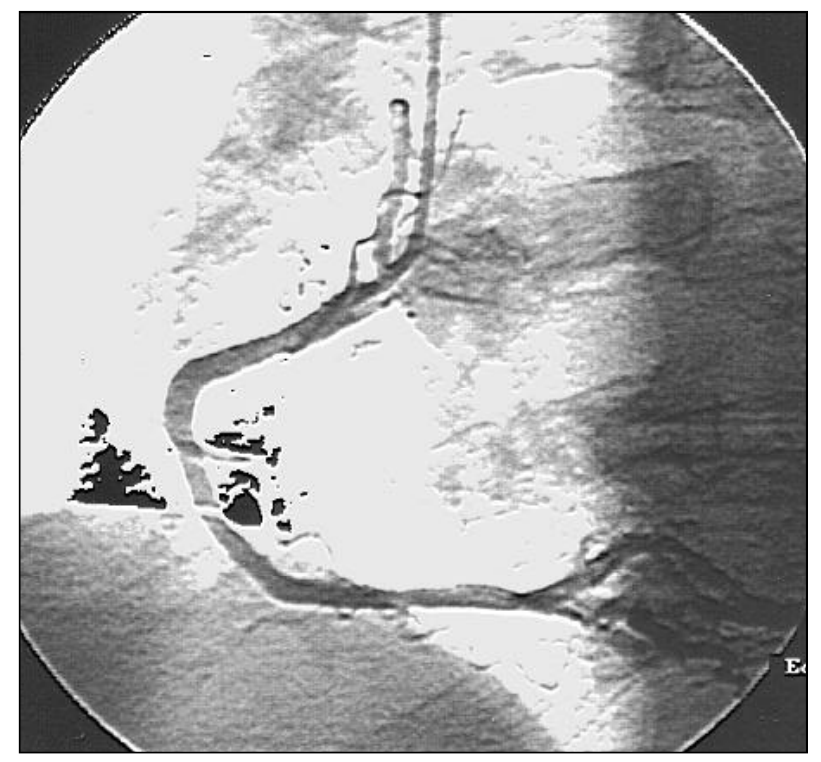

Fig. 4 - Right coronary angioplasty with stent implantation.

sinus of Valsalva, and congenital coronary artery atresia or stenosis $2,8,9$.

In human hearts, the anterior descending branch is the vessel with the most constant origin, course, and distribution ${ }^{5}$. In the case of an anomalous origin of the anterior descending branch from the right sinus of Valsalva or from the right coronary artery, its trajectory may have 2 variants: to pass between the aorta and the pulmonary artery, or to be anterior to the pulmonary trunk before reaching the anterior interventricular sulcus ${ }^{2}$.

In the case of a dual anterior descending coronary artery, 2 branches provide the usual distribution of that coronary artery as follows: 1) one branch, the short anterior descending branch, ends at the beginning of the anterior 


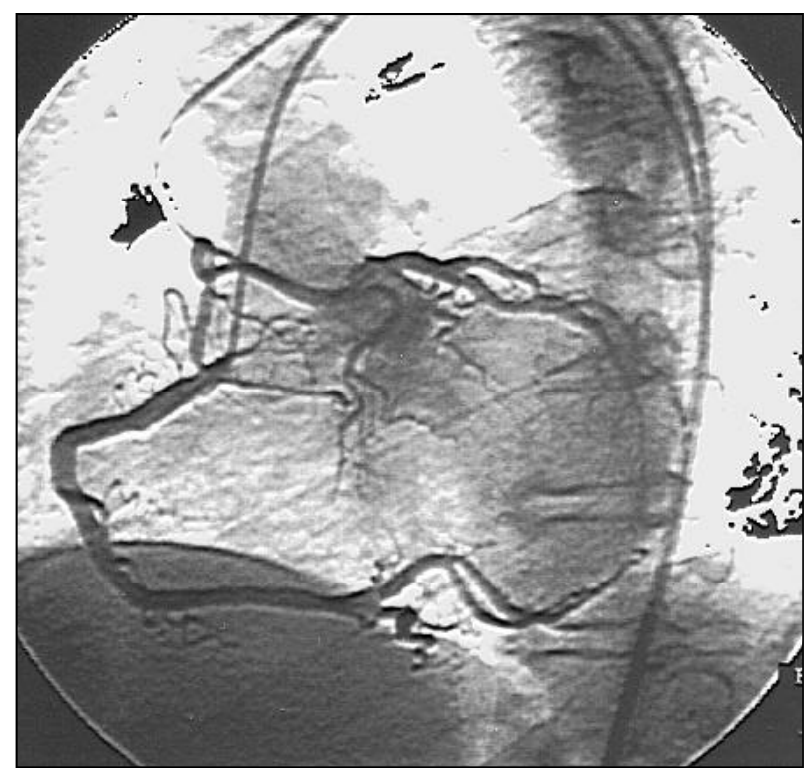

Fig. 5 - Primary success of right coronary angioplasty.

interventricular sulcus; 2) a second longer branch has a variable course beside the anterior interventricular sulcus and returns to this sulcus distally ${ }^{4}$.

This anomaly was classified into 4 types by SpindolaFranco et $\mathrm{al}^{10}{ }^{10}$. In types I, II, and III, the anterior descending branch originates from the trunk of the major anterior descending coronary artery (the anterior descending coronary artery itself). The case reported fits type IV dual anterior descending coronary artery, which is a rare anomaly. In this type, the long anterior descending branch originates in the right sinus of Valsalva or in the right coronary artery.

The clinical influence of this anomaly is still controversial in the literature. It was initially considered benign ${ }^{2}$; however, some authors associate it with stable angina, acute myocardial infarction, and postinfarction angina. Mello et al ${ }^{6}$ reported 2 cases with clinical, electric, and scintigraphic evidence of myocardial ischemia, in which the anterior descending branch originated from the right sinus of Valsalva.

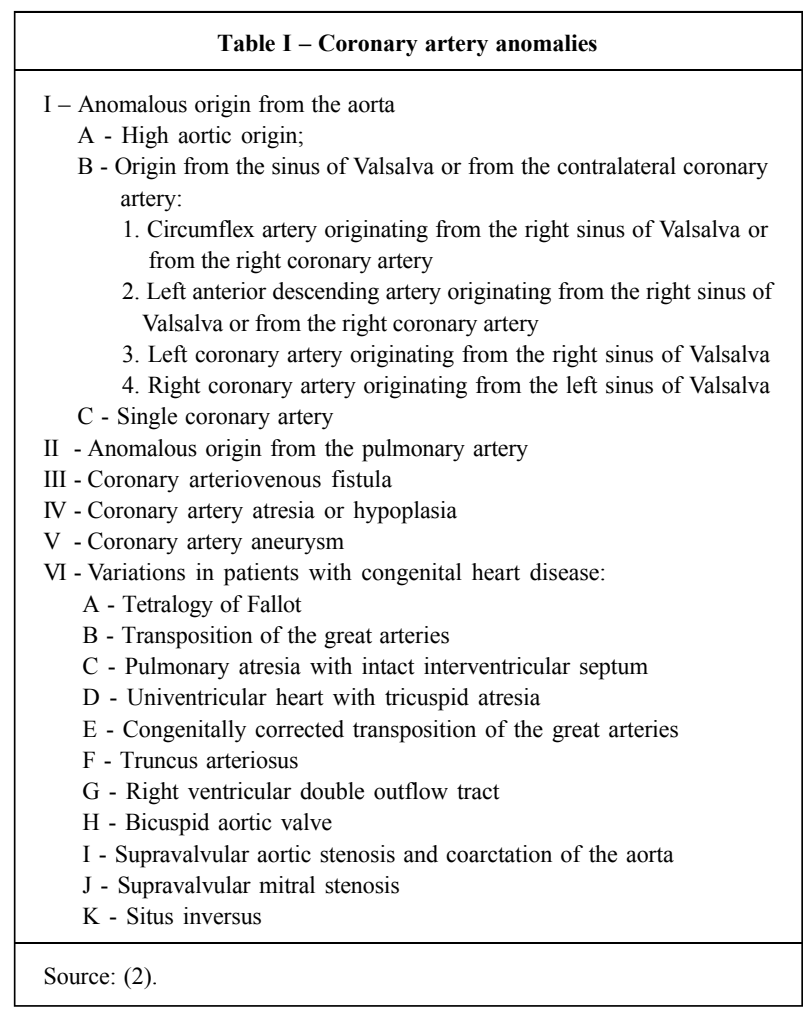

Oliveira et al ${ }^{1}$ reported that the right side origin of the anterior descending branch is a significant anomaly that may cause myocardial ischemia. Coyle et al ${ }^{7}$ correlated the origin of the anterior descending branch in the right sinus of Valsalva or in the right coronary artery with acute myocardial infarction and postinfarction angina.

In the literature reviewed, only 2 cases of a dual left anterior descending coronary artery associated with obstructive coronary disease were found ${ }^{3}$, ours being the third case reported.

Therefore, anomaly of the anterior descending coronary artery may be considered as a hypothesis in the differential diagnosis of angina and ischemia of the anterior wall.

\section{References}

1. Oliveira SF, Ramires JA, Meneghetti JC, et al. Anomalias congênitas de artérias coronárias: possível causa de insuficiência coronariana. Arq Bras Cardiol 1988; 50: $285-91$.

2. Douglas Jr. DS, Franch RH, King III SB. Coronary artery anomalies. In: King III SB, Douglas Jr. DS. Coronary Arteriography and Angioplasty. New York: McGraw Hill Text; (Chapter 3), 1985: 33-85.

3. Tutar E, Gulec S, Pamir G, et al. A case of type IV dual left anterior descending artery anomalous origin associated with the presence of coronary atherosclerosis. J Invas Cardiol 1999; 11: 631-4.

4. Bastos LC, Ariê S, Martins JF, et al. Dupla origem do ramo descendente anteriordas coronárias esquerda e direita - associada a origem anômala à direita do ramo circunflexo. Arq Bras Cardiol 1996; 67: 407-9.

5. Ilia $\mathrm{R}$, et al. Mid left anterior descending coronary artery originating from right coronary artery. Int J Cardiol 1991; 33: 162-5.
6. Mello SC, Carvalho VB, Godoy M, et al. Origem anômala da artéria descendente anterior em artéria coronária direita: relato de dois casos. Arq Bras Cardiol 1981; 37: 467.

7. Coyle L, Thomas WJ. Anomalous left anterior descending coronary artery: malignant hospital course of a not so benign anomaly. Catheter Cardiovasc Interv 2000; 51: 468-70

8. Bittel JA, Levin DC. Coronary arteriography. In: Braunwald E. Heart Disease. $5^{\text {th }}$ Ed. (Chapter 8), 1980: 240-72.

9. Levin DC, et al. Hemodynamically significant primary anomalies of the coronary arteries. Angiographic aspects. Circulation 1978; 58: 25-34.

10. Spindola-Franco H, Grose R, Salomon N. Dual left anterior descending coronary artery: angiographic description of important variants and surgical implications. Am Heart J 1983; 105: 445-55. 